\title{
BIOLOGICAL CHARACTERISTICS OF THE JAPANESE SCAD Decapterus maruadsi IN THUAN AN ESTUARY, THUA THIEN HUE PROVINCE
}

\author{
Tran Thi Ngoc Anh ${ }^{1,2}$, Nguyen Xuan Huan 1,3, \\ Tran Trung Thanh ${ }^{1,4}$, Nguyen Thanh Nam ${ }^{1,3,4, *}$ \\ ${ }^{1}$ Faculty of Biology, VNU University of Science, Ha Noi, Vietnam \\ ${ }^{2}$ Research Institute for marine fisheries, Hai Phong, Vietnam \\ ${ }^{3}$ The Biological Museum, VNU University of Science, Ha Noi, Vietnam \\ ${ }^{4}$ Center of Life Science Research (CELIFE), VNU University of Science, Ha Noi, Vietnam \\ Received 24 June 2019, accepted 21 October 2019
}

\begin{abstract}
A total of 257 Decapterus maruadsi individuals of collected from Thuan An estuary in Phu Vang District, Thua Thien Hue Province were analyzed. Results showed that the fork length ranged from $90 \mathrm{~mm}$ to $215 \mathrm{~mm}$ (160.2 $\mathrm{mm}$ on average) and mainly in the $140-180 \mathrm{~mm}$ range $(86.8 \%)$. Of three age groups $\left(0^{+}\right.$to $\left.2^{+}\right)$, the fished stock belongfrom is primarily to the $1^{+}$age group $(63.8 \%)$ and $0^{+}$age group (28.8\%). Of five stomach fullness levels ( 0 to 4$)$, the second and fourth degree made up significantly proportions, being $29.6 \%$ and $31.5 \%$, respectively. For the five fat levels ( 0 to 4$)$, the fourth degree made up $86.0 \%$. The females to males ratio was $1.00: 1.42$. von Bertalanffy's growth model followed the equation: $\mathrm{L}_{\mathrm{t}}=203.77 \times\left(1-\mathrm{e}^{-0.3747(\mathrm{t}+3.0272)}\right)$.
\end{abstract}

Keywords: Decapterus maruadsi, biological characteristics, Thuan An estuary.

Citation: Tran Thi Ngoc Anh, Nguyen Xuan Huan, Tran Trung Thanh, Nguyen Thanh Nam, 2019. Biological characteristics of the Japanese scad Decapterus maruadsi in Thuan An estuary, Thua Thien Hue Province. Academia Journal of Biology, 41(4): 125-130. https://doi.org/10.15625/2615-9023/v41n4.13891.

*Corresponding author email: nguyenthanhnam@hus.edu.vn

(O2019 Vietnam Academy of Science and Technology (VAST) 


\section{INTRODUCTION}

Decapterus maruadsi,a coastal pelagic scad of commercial importance (Carpenter \& Niem , 1999) and high nutritional value, is commonly harvested in tropical and temperate seas in South East Asian countries. Among the 4 Decapterus species of Vietnam, Decapterus maruadsi produces the highest output, about $10 \%$ of production from bottom trawl (Bui Dinh Chung et al., 1998), . Recently, several researches on biological characteristics of $D$. maruadsiwere published by Le Tu Cuong (1985) in East sea; Bui Dinh Chung (1988), Nguyen Viet Nghia (1999), Hoang Ngoc Son \& Vu Viet Ha (2016) in Tonkin gulf. However, there was not any information about Decapterus maruadsi in Thua Thien Hue province. This research studied to determine length-weight relationship, age structure, growth parameters, sexual ratio and reproduction of $D$. maruadsi to provide input data for assessing both stock and exploitation status of this species in Thua Thien Hue Province.

\section{MATERIALS AND METHODS}

A total of 257 individuals of Decapterus maruadsi were randomly collected from catches of fishmen during field survey in the neashore area of Thua Thien Hue Province from $20^{\text {th }}$ to $28^{\text {th }}$ July 2015 .

The total length (L), fork length (FL), standard length (SL) and total weight (W) under good conditions of fish samples were measured according to the measurement method of FAO (Carpenter \& Niem, 1999). Individuals were anatomized to determine sex, stage of gonad maturity (Nilcolsky, 1963), the degree of fat and the degree of stomach fullness. Weights were measured again $\left(\mathrm{W}_{\mathrm{E}}\right)$ after removing all internal organs.

Scale samples were collected above the lateral line and below the middle of the spiny dorsal fin. Scales were firstly immersed into Sodium hydroxide solution $3-5 \%$ for 30 minutes. 5 normal and complete scales were then placed on a slide with ridges down and viewed through a microscope micrometer to determine the age by counting the rings (Scheneider, 2000).

For the length-weight equation $\left(\mathrm{W}=\mathrm{a} \times \mathrm{L}^{\mathrm{b}}\right.$, where: $\mathrm{W}=$ total weight $(\mathrm{g}) ; \mathrm{L}=$ total length (mm); $\mathrm{a}$ and $\mathrm{b}=$ constant and coefficient), least square method was used to determine a and $b$.

Parameters of the von Bertalanffy growth equations: $\mathrm{L}_{\mathrm{t}}=\mathrm{L}_{\infty}\left\{1-\mathrm{e}_{0}^{-\mathrm{k}(\mathrm{t}-\mathrm{t})}\right\}$ and $\mathrm{W}_{\mathrm{t}}=\mathrm{W}_{\infty}\{1-$ $\left.\mathrm{e}^{-\mathrm{k}(\mathrm{t}-\mathrm{t})}\right\}^{\mathrm{b}}$ (where: $\mathrm{L}_{\mathrm{t}}$ and $\mathrm{W}_{\mathrm{t}}=$ fish length and weight at the age $t$, respectively; $\mathrm{L}_{\infty}$ and $\mathrm{W}_{\infty}=$ asymptotic length and weight; $\mathrm{k}=$ coefficient of catabolism; $t_{0}=$ arbitrarily adopted origin of growth curve; $b=$ exponent in the lengthweight relationship) were determined using the methods of Berverton and Holt as reviewed in Sparre (1993).

Feeding and production analysis follow Pravdin (1973), in which the feeding intensity and stage of sexual maturity of fishes were presented by 5 -grades scale (from 0 to 4 ) and 6-grades scale (from I to VI), respectively.

\section{RESULTS AND DISCUSSION}

The fork length of Decapterus maruadsi from the research area ranged from $90 \mathrm{~mm}$ to $215 \mathrm{~mm}$ and mainly from $140-180 \mathrm{~mm}$ $(86.8 \%)$ (table 1). The mean of fork length was $160.2 \mathrm{~mm}$., the longer average fork length of round scad in our research (July 2015). The means of fork length in males and females were $158.3 \mathrm{~mm}$ and $164.2 \mathrm{~mm}$, respectively, both longer than those in Tonkin gulf (Hoang Ngoc Son, 2013) (145.4 mm and $148.7 \mathrm{~mm}$ ) . This may be due to fishes in the Thua Thien Hue having spawned at an earlier time than those in Tonkin gulf. In addition, the duration of the collecting period and the number of samples may not be large enough.

The age of 257 specimens were ranged from $0^{+}$to $2^{+}$, with age $1^{+}$fishes the most common, accounting for $63.8 \%$ of the total. The age $2^{+}$group was least present $(7.4 \%)$ (table 2). 
Table 1. Fork length groups of Decapterus maruadsi

\begin{tabular}{|c|c|c|c|}
\hline Group & Fork length group $(\mathrm{mm})$ & Number of specimens & $\%$ \\
\hline 1 & $80 \leq \mathrm{FL}<100$ & 5 & 2.0 \\
\hline 2 & $100 \leq \mathrm{FL}<120$ & 4 & 1.6 \\
\hline 3 & $120 \leq \mathrm{FL}<140$ & 9 & 3.5 \\
\hline 4 & $140 \leq \mathrm{FL}<160$ & 107 & 41.6 \\
\hline 5 & $160 \leq \mathrm{FL}<180$ & 116 & 45.1 \\
\hline 6 & $180 \leq \mathrm{FL}<200$ & 11 & 4.3 \\
\hline 7 & $200 \leq \mathrm{FL}<220$ & 5 & 1.9 \\
\hline Total & $90-215$ & 257 & 100 \\
\hline
\end{tabular}

Table 2. Fork length ranges of Decapterus maruadsi

\begin{tabular}{|c|c|c|c|}
\hline Age group & Fork length range $(\mathrm{mm})$ & Number of specimens & Percentage $(\%)$ \\
\hline $0^{+}$ & $90-157$ & 74 & 28.8 \\
\hline $1^{+}$ & $156-189$ & 164 & 63.8 \\
\hline $2^{+}$ & $170-215$ & 19 & 7.4 \\
\hline
\end{tabular}

\section{Length-weight relationship}

Relationships between fork length (FL) and weight $(\mathrm{W})$ were found to be:

$\mathrm{W}=0.0004 \times \mathrm{L}^{2.3310}\left(\mathrm{R}^{2}=0.9291\right)($ whole stock).

$\mathrm{W}=0.0005 \times \mathrm{L}^{2.2752}\left(\mathrm{R}^{2}=0.8589\right)$ (for female).

$\mathrm{W}=0.0004 \times \mathrm{L}^{2.3509}\left(\mathrm{R}^{2}=0.9457\right)$ (for male).

The $\mathrm{R}$ value of all equations were higher than 0.9 , indicating good fits.
A value of $b<3$ indicate that at the beginning stage, fish mainly increased in length. After having reached a certain size, body weight increased faster than length. This relationship differed between males and females.

The $b$ coeffecient was $<3$ in other researches in other researches, except for two sites (table 3). This may occur due to different number of samples, sampling time and duration.

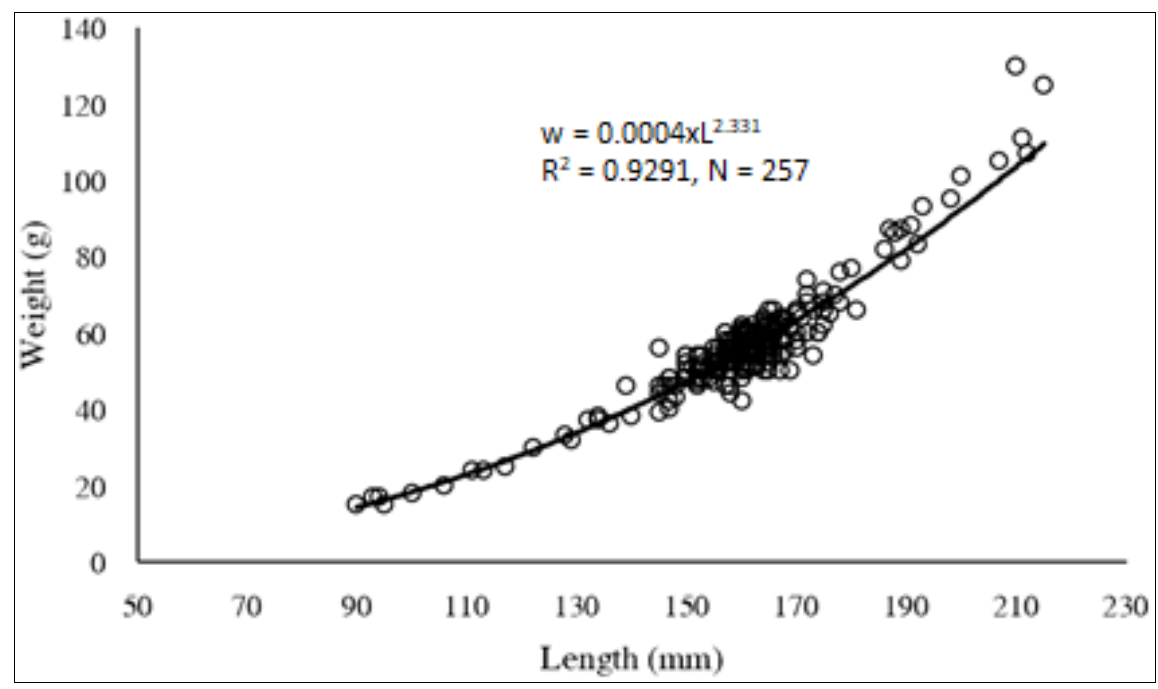

Figure 1. Relationship between weight and fork length of D. maruadsi in whole stock 
Table 3. Comparing the coefficients of length-weight relationship model in different studies

\begin{tabular}{|l|c|c|c|c|c|c|c|c|}
\hline \multirow{2}{*}{ Study sites } & \multicolumn{2}{c|}{ Whole stock } & \multicolumn{2}{c|}{ Male } & \multicolumn{2}{c|}{ Female } & \multicolumn{2}{c|}{ Juvenile } \\
\cline { 2 - 9 } & $\mathrm{a}$ & $\mathrm{b}$ & $\mathrm{a}$ & $\mathrm{b}$ & $\mathrm{a}$ & $\mathrm{b}$ & $\mathrm{a}$ & $\mathrm{b}$ \\
\hline Thuan An estuary (this study) & 0.0004 & 2.331 & 0.0004 & 2.3509 & 0.0005 & 2.2752 & - & - \\
\hline $\begin{array}{l}\text { Tonkin gulf (2012-2013) } \\
\text { (Hoang Ngoc Son \& Vu Viet } \\
\text { Ha, 2016) }\end{array}$ & $0.8 \times 10^{-5}$ & 3.106 & $6.2 \times 10^{-5}$ & 2.6959 & $6.1 \times 10^{-5}$ & 2.6955 & $4.6 \times 10^{-5}$ & 3.1975 \\
\hline $\begin{array}{l}\text { Tonkin gulf (1999) (Nguyen } \\
\text { Viet Nghia, 1999) }\end{array}$ & & 2.83 & - & 2.87 & - & 2.84 & - & - \\
\hline $\begin{array}{l}\text { Tonkin gulf (1998) (Bui } \\
\text { Dinh Chung, 1998) }\end{array}$ & - & 2.533 & - & - & - & - & - & - \\
\hline $\begin{array}{l}\text { Thanh Hoa Province (2014) } \\
\text { (Le Duc Giang, 2014)) }\end{array}$ & 0.0096 & 3.096 & 0.011 & 3.033 & 0.009 & 3.121 & - & - \\
\hline $\begin{array}{l}\text { South of Central Vietnam } \\
\text { (Bui Dinh Chung, 1998) }\end{array}$ & - & 2.602 & - & - & - & - & - & - \\
\hline
\end{tabular}

\section{Estimation of growth parameters}

von Bertalanffy length and weight growth equations for the caught fishes were calculated to be:

$$
\begin{gathered}
\mathrm{L}_{\mathrm{t}}=203.77 \times\left(1-\mathrm{e}^{-0.3747(\mathrm{t}+3.0272)}\right) \\
\mathrm{W}_{\mathrm{t}}=92.71 \times\left(1-\mathrm{e}^{-0.3747(\mathrm{t}+3.0272)}\right)^{2.5291}
\end{gathered}
$$

The $\mathrm{L}_{\infty}$ value in this study $(203.77 \mathrm{~mm})$ is lower than previous values: $243 \mathrm{~mm}$ in center gulf (Bui Dinh Chung ,1998), $286 \mathrm{~mm}$ in near-shore and $258 \mathrm{~mm}$ in Thuan Hai area (Binh Thuan and Ninh Thuan Provinces) (Nguyen Xuan Huan, 1996). This partly shows that this species is under pressure by exploitation.

\section{Feeding intensity}

\section{Percentage of degree fullness (\%)}
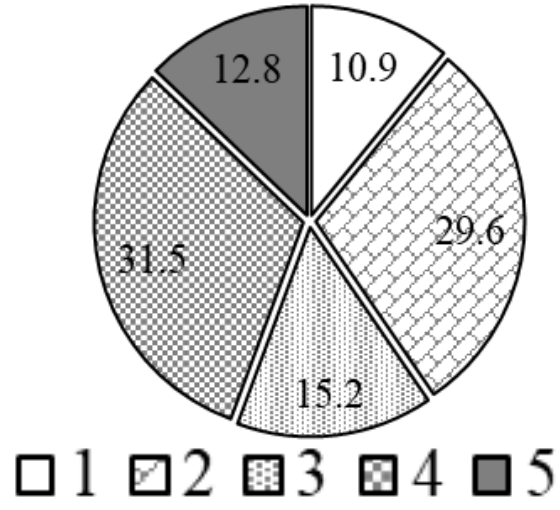

Figure 2. Degree of fullness of stomach in caught fish
Most collected stomachs were of degree 1 and 3 (29.6\% and $32.5 \%$, respectively). $10.9 \%$ of stomachs were totally empty (Figure 2). It can be infer that there was significant competition in catching food between big and small individuals, leading to a clear division between second and fourth degree of stomach fullness.

\section{Fat analysis}

The fat level of 257 fish individuals was quite high. 221 samples were at level 3 (86.0\%). Level 0,1 and 2 accounted for $13.6 \%$; only 01 male sample was at the level 4 $(0.4 \%)$. The male and female percentages were $40 \%$ and $60 \%$ at level 0 and $60 \%$ and $40 \%$ at level 1.

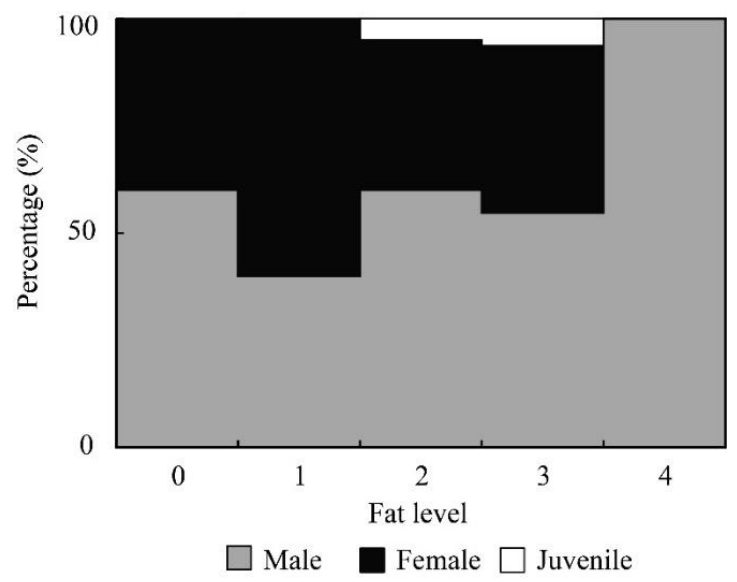

Figure 3. Male, female and juvenile percentages of fat levels 


\section{Reproduction analysis}

The sex ratio of D. maruadsi was unequal, being 1.00:1.42 with 100 females, 142 males and 15 juveniles. $87.16 \%$ was at gonad stage II; mostly in the $1^{+}$age group (first reproduction season), which is consistent with the end of the breeding season in Vietnam (Nguyen Viet Nghia (1999), Hoang Ngoc Son \& Vu Viet Ha (2016)). This also shows that exploitation in the study area during the time of sampling did not affect the resupplementation of the population.

\section{CONCLUSION}

The samples of Japanese scad collected in Thuan An estuary in July were mainly $140-180 \mathrm{~mm}$ and most of individuals were in the 1+ old group. Von Bertalanffy growth equation of Decapterus maruadsi in this area was $\mathrm{Lt}=203.77 \times\left(1-\mathrm{e}^{-0.3747(\mathrm{t}+3.0272)}\right)$, the $\mathrm{L}_{\infty}=$ $203.77 \mathrm{~mm}$ which was smaller than $\mathrm{L}_{\infty}$ of some studies estimated. At this time, the fishes were relatively high fat level. In July, the population of Japanese scad in Thuan An estuary area had a higher proportion of male fish and most fish were in stage 2 of gonad maturity.

\section{REFERENCES}

Bui D. C., Chu Tien Vinh, Nguyen Phi Dinh, 1998. Some biological characteristics and fisheries status of round scad (Decapterus maruadsi) Indian mackerel (Rastrelliger kanagurta) and Tunas in seawaters of Viet Nam. Collection of researches for marine fishes. Agriculture Publishing, Vol 1: pp.132-141.

Carpenter K. E., Niem V. H., 1999. FAO species identification guide for fishery purposes. The living marine resources of the Western Central Pacific. Volume 3. Batoid fishes, chimaeras and bony fishes part 1 (Elopidae to Linophrynidae), Food and Agriculture Organization of the United Nations.

Capenter, K. E., Niem, V. H.,1999. FAO species identification guide for fishery purposes. The living marine resources of the Western Central Pacific. The living marine resources of the Western Central Pacific: vol 4 bony fishes part 2 (Mugilidae to Carangidae). Food and Agriculture Organization of the United Nations.

Chen G. B., Quiu Y. S., 2003. Study on growth mortality and reasonable utilization of Decapterus maruadsi in northern continental shelf waters of South China Sea, Journal of Oceanography in Taiwan strait, pp. 32.

Hoang N. S., Vu Viet Ha, 2016. Biological characteristics of round scad decapterus maruadsi (Temminck \& Schlegel, 1843) in the tonkin gulf. Vietnam Marine Science and Technology, 16(2): 205-213.

Kimura S., Katahira K., Kuriiwa K., 2013. The red-fin Decapterus group (Perciformes: Carangidae) with the description of a new species, Decapterus smithvanizi. Ichthyological Research, Vol 60: pp. 363-379.

Le D. G., Vu Viet Ha, Tran Van Cuong, 2014. Determining the spawning season of some marine fishes in Thanh Hoa province and adjunction waters. Agriculture Publishing, Vol 21: 90-95.

Le T. C., 1885. Growth of round scad in East Eea Vietnam. Documentary sources of Research Institute for Marine fisheries, pp. 52.

Nguyen P. D., 1991. Biological characteristics of Japanese scad Decapterus maruadsi in seawater in Vietnam. The $3^{\text {nd }}$ National Conference on Marine, Science report Collection, Biology and Marine Biotechnology, Marine Ecology, Vol 1: pp. 36-45.

Nguyen P. D., 1998. Growth of round scad in East sea Vietnam. Marine researches collection, pp. 209-226.

Nguyen X. H., 1996. Growth and stock dynamic and the catch ability of some 
commercial fish species in the waters of Binh Thuan - Ninh Thuan, summarizing the dissertation thesis of Candidate of Biological Sciences, University of Science - VNU Hanoi, pp.24.

Nguyen V.N., 1999. Some biological characteristics of Japanese scad Decapterus maruadsi and yellowstripe scad Selaroides leptolepis in Vietnam.
Documentary sources of Research Institute for Marine fisheries, p.151.

Scheneider J. C., Laaram P. W., Gowing H., 2000. Age and growth methods and state average, Manual of fishery survey method II: with periodic updates, Michigan Department of Natural Resources, Fisheries Special Report 25, Ann Arbor, pp. 148. 